\title{
Leaf Area Index Specification for Use in Mesoscale Weather Prediction Systems
}

\author{
CHRISTOPH KNOTE \\ Laboratory for Air Pollution/Environmental Technology, Empa, Duebendorf, Switzerland \\ Giovanni BonAfE AND FRAnCESCA Di GiUseppe \\ ARPA-Servizio IdroMeteoClima, Bologna, Italy
}

(Manuscript received 1 December 2008, in final form 5 May 2009)

\begin{abstract}
The energy budget at the surface is strongly influenced by the presence of vegetation, which alters the partitioning of thermal energy between sensible and latent heat fluxes. Despite its relevance, numerical weather prediction (NWP) systems often use only two parameters to describe the vegetation cover: the fractional area of vegetation occupying a given pixel and the leaf area index (LAI). In this study, the Consortium for Small-Scale Modelling (COSMO) limited-area forecast model is used to investigate the sensitivity of regional predictions to LAI assumptions over the Italian peninsula. Three different approaches are compared: a space- and time-invariant LAI dataset, a LAI specification based on Coordination of Information on the Environment (CORINE) land classes, and a Moderate Resolution Imaging Spectroradiometer (MODIS) satellite-retrieved dataset. The three approaches resolve increasingly higher moments both in time and space of LAI probability density functions. Forecast scores employing the three datasets can therefore be used to assess the required degree of accuracy needed for this parameter. The MODIS dataset is the only one able to capture the expected vegetative cycle that is typical of the Mediterranean ecosystem and noticeably improves the $850-\mathrm{hPa}$ temperature and humidity forecast scores up to $+72 \mathrm{~h}$ forecast time. This suggests that accounting for LAI temporal and spatial variability could potentially improve the prevision of lower-level variables. Nevertheless, model biases of 2-m screen temperatures are not substantially reduced by the more detailed LAI specification when comparisons to synoptic observing stations are performed. Using long-term measurements collected by the CarboEurope project, a detailed verification of sensible and latent heat flux predictions is also presented. It shows that the desirable positive impact arising from a better LAI specification is nullified by the large uncertainties in the initialization of the soil moisture, which remains a crucial parameter for the reduction of screen-level biases.
\end{abstract}

\section{Introduction}

Observational evidence shows that the intensity and spatial distribution of surface sensible heat fluxes can drive mesoscale circulations, such as sea breezes or thermally induced upslope flows (Segal et al. 1988), and can trigger and sustain localized convection (Hammer 1970; Segal et al. 1995). The prediction of such localized phenomena is difficult even for a regional weather forecasting system with a resolution scale approaching

Corresponding author address: Christoph Knote, Laboratory for Air Pollution/Environmental Technology, Empa Swiss Federal Laboratories for Materials Testing and Research, Ueberlandstr. 129, 8600 Duebendorf, Switzerland.

E-mail: christoph.knote@empa.ch a few kilometers. Most of the difficulties arise from the lack of adequate information on the surface properties, such as soil type, soil humidity, and vegetation characteristics (Masson et al. 2003). In particular, even if the contribution of plant transpiration is crucial for the partition of thermal energy between sensible and latent heat fluxes (i.e., the Bowen ratio), vegetation variability is often completely neglected or only poorly described. The importance of an accurate description of land surface parameters in numerical weather prediction (NWP) models has already been emphasized by different authors several years ago (e.g., Wetzel and Chang 1988; Kurkowski et al. 2003). Those studies indicate that even climatological data series of such parameters do not capture the variability necessary for an accurate description of the surface-atmosphere energy exchange. 
This study focuses on the modeling of the leaf area index (LAI) as one of the key parameters. There are others of equal importance for the correct description of the surface energy balance (e.g., the soil moisture and the vegetation fraction; see Crawford et al. 2001 and references therein). The need for their accurate description in a model is of similar importance, and their current implementations will probably exhibit comparable deficits.

Recent land surface parameterizations require the specification of two major vegetation parameters: vegetation type and amount (Sellers et al. 1986; Noilhan and Planton 1989; Sellers et al. 1996). Vegetation type classification is performed by using available global vegetation maps based on ground observations to create a set of land cover classes (e.g., Commission of the European Communities 1995; Loveland et al. 2000; Bartholomé and Belward 2005). Vegetation amount is described using the fractional area $f_{\text {veg }}$ of vegetation occupying a given pixel. In this study, the operational $f_{\text {veg }}$ dataset of the Consortium for Small-Scale Modelling (COSMO) model is used with all three LAI descriptions to avoid the influence of differences therein. The LAI is defined as the area of leaf surface in a grid cell in comparison to the vegetated part of the gridcell area. Because distributions of $f_{\text {veg }}$ and LAI are globally and seasonally unknown, the vegetation type is usually used also to attribute tabulated values to these two variables (Viterbo and Beljaars 1995). Those values are often derived from literature findings or based on limited field studies. A land cover classification, therefore, is equivalent to a vegetation property classifier.

In this empirical approach, some assumptions are made. First, for a given land cover, it is accepted that an unambiguous range of LAI and $f_{\text {veg }}$ values can be defined, even if these classes are not actually derived by imposing constraints on LAI and $f_{\text {veg }}$ values themselves. Second, it is taken for granted that a few classes can be comprehensive in representing vegetation characteristic across several world regions. So "coniferous forest," for example, is identical in terms of vegetation characteristics whether describing Alpine or North American woodland. Finally, the seasonal variability of vegetation density related to plant phenological evolution is usually simulated with empirical modulation functions that are only dependent on latitude and elevation.

Satellite products can guarantee a higher temporal and spatial data coverage. Datasets containing information on land surface characteristics have been produced from the Moderate Resolution Imaging Spectroradiometer (MODIS) on board the Terra satellite since 2000 (Knyazikhin et al. 1999). Among the various MODISderived vegetation indices, the global leaf area index product is an 8-day composite with a spatial resolution of
$1 \mathrm{~km}$ on a sinusoidal grid. Considering its high spatial and temporal resolution, MODIS data can potentially improve the representation of land surface parameters at both global and regional scales, as demonstrated by, for example, the successful implementation of Kurkowski et al. (2003). The aim of this work is therefore to use this product to assess the impact of different LAI specifications on weather forecasts for the Italian peninsula using the regional model COSMO. Three different approaches are compared: a space- and time-invariant LAI dataset (FIX), an LAI specification based on land cover classes (LCB), and a new MODIS-based dataset (MOD). The LCB approach resembles the currently operational vegetation parameterization in the COSMO model.

As with many other land surface parameters, because LAI is not a directly observable parameter, the direct validation of the three datasets is difficult to perform, if it is feasible at all. An indirect validation is therefore performed following a twofold approach. First, the three datasets are evaluated in their capability of capturing the expected vegetative cycle for the Italian region. Second, using a long-term run of 30 days between 1 and 30 June 2005, improvements in weather forecasts are quantified by means of reductions in forecast minus analysis and observation errors. In particular, comparisons are performed against latent and sensible surface flux measurements of the CarboEurope project (Papale et al. 2006) and screen-level temperatures of the synoptic observing network.

In the next section, the three leaf area index datasets are presented. They are compared in terms of their relative merits in describing the expected vegetative cycle of the Italian landscape. The validation of the three datasets in terms of forecast improvements is reported in section 3. Section 4 draws the conclusions of this paper.

\section{Leaf area index datasets}

\section{a. Description}

Three LAI datasets are created of increasing complexity. A "level 0" LAI is held constant over the whole modeling domain at a mean value of 3 and does not include seasonal modulation (FIX). This dataset is used as a control to quantify the zero-order impact of LAI variability.

The second LAI dataset is created following the land cover approach (LCB). It uses the land cover dataset produced as an outcome of the Coordination of Information on the Environment (CORINE) project by the Commission of the European Communities (1995). It provides a comprehensive land cover specification for 
the year 2000 covering the territory of the member states of the European Union (EU), including Italy. It consists of 44 classes and is originally delivered as vector data, describing land features to a resolution of $100 \mathrm{~m}$. For use in this analysis, it has been transformed to a regular grid with a nominal gridcell size of $0.5 \mathrm{~km}$. To each pixel maximum (plant vegetation period) and minimum (plant resting period), LAI values are attributed using data from the Ecoclimap project (S. Faroux 2007, personal communication; Champeaux et al. 2005). ${ }^{1}$ The LAI seasonal variability is simulated by means of an empirical function [a more thorough description can be found in Doms et al. (2004)]:

$$
\begin{aligned}
\operatorname{LAI}\left(\phi, J_{d}, \Phi_{s}\right)= & \mathrm{LAI}_{\text {min }}+\left(\mathrm{LAI}_{\text {max }}-\mathrm{LAI}_{\text {min }}\right) \\
& \times f_{v}\left(\phi, J_{d}\right) f_{h}\left(\Phi_{s}\right),
\end{aligned}
$$

where $\phi$ is the geographic latitude, $\Phi_{s}$ is the geopotential height of the surface, and $f_{h}$ is the height reduction function. The term $f_{v}$ provides the annual development through

$$
\begin{aligned}
& f_{v}\left(\phi, J_{d}\right) \\
& \quad=\max \left[0.0, \min \left(1.0, C \sin \left\{\pi \max \left[0.0,\left(J_{d}-V_{s}\right) / V_{l}\right]\right\}\right)\right],
\end{aligned}
$$

where $J_{d}(\phi)$ is the current yearday, $V_{s}(\phi)$ is the starting yearday of the vegetation period, and $V_{l}$ is its length. The terms $V_{s}(\phi)$ and $V_{l}$ are estimated by using the World Meteorological Organization (WMO) climatic atlas of Europe (WMO 1970) and vary with the geographic latitude $\phi$. Equation (1) is constructed so that southern regions are characterized by longer vegetation periods, and a reduction of LAI is applied at high altitudes. The annual cycle created in Eq. (2) results in a flattened sine curve with its maximum throughout summer and minimum in winter. The amplitude is given by the tabulated LAI values. Table 1 summarizes the CORINE classes and their assigned Ecoclimap LAI minimum and maximum values.

The third LAI dataset (MOD) is constructed by using products retrieved from the MODIS sensor on board the Terra satellite. The global leaf area index product MOD15A2 is an 8-day composite (1 year has 45 MODIS days) with a spatial resolution of $1 \mathrm{~km}$ on a sinusoidal grid. The product version 4 is employed here. The algorithm used to calculate the LAI (Knyazikhin et al. 1999) uses a

\footnotetext{
${ }^{1}$ The Ecoclimap approach uses a combination of literature LAI values and actual observations obtained from the Advanced Very High Resolution Radiometer (AVHRR) normalized difference vegetation index (NDVI; Masson et al. 2003).
}

TABLE 1. CORINE classes with prescribed minimum and maximum LAI values.

\begin{tabular}{lll}
\hline \hline & & \multicolumn{1}{c}{ LAI } \\
\hline Min & Max & \\
\hline 0.44 & 0.86 & Continuous urban fabric \\
0.71 & 2.15 & Discontinuous urban fabric \\
0.51 & 1.68 & Industrial or commercial units \\
0.71 & 2.03 & Road and rail networks and associated land \\
0.23 & 0.46 & Port areas \\
0.69 & 1.82 & Airports \\
0.81 & 2.24 & Mineral extraction sites \\
0.56 & 2.29 & Dump sites \\
0.69 & 2.15 & Construction sites \\
0.69 & 1.90 & Green urban areas \\
0.81 & 2.12 & Sport and leisure facilities \\
0.68 & 2.78 & Non-irrigated arable land \\
0.97 & 2.60 & Permanently irrigated land \\
0.20 & 3.93 & Rice fields \\
0.82 & 2.21 & Vineyards \\
0.98 & 2.15 & Fruit trees and berry plantations \\
1.14 & 1.94 & Olive groves \\
1.12 & 3.06 & Pastures \\
0.91 & 2.50 & Annual crops associated with permanent crops \\
0.88 & 3.11 & Complex cultivation \\
0.98 & 3.17 & Mixed cultivated and natural land \\
1.27 & 2.17 & Agro-forestry areas \\
1.21 & 3.45 & Broad-leaved forest \\
1.67 & 3.32 & Coniferous forest \\
1.57 & 3.50 & Mixed forest \\
1.01 & 2.52 & Natural grassland \\
1.04 & 2.44 & Moors and heathland \\
1.13 & 1.94 & Sclerophyllous vegetation \\
1.09 & 2.85 & Transitional woodland shrub \\
0.72 & 1.98 & Beaches, dunes, and sand plains \\
0.22 & 0.56 & Bare rocks \\
0.57 & 1.40 & Sparsely vegetated areas \\
1.36 & 2.38 & Burnt areas \\
0.04 & 0.10 & Glaciers and perpetual snow \\
0.85 & 2.80 & Inland marshes \\
1.08 & 2.89 & Peatbogs \\
0.79 & 1.69 & Salt marshes \\
0.96 & 1.80 & Salines \\
0.70 & 2.91 & Water courses \\
\hline & &
\end{tabular}

classification of the land surface into six biome types according to canopy geometry (trees, shrubs, pastures, etc.) and a sophisticated radiative transfer model. ${ }^{2}$ Sets v18h04, v18h05, v19h04, and v19h05 cover the COSMO-I ${ }^{3}$ domain. The MODIS data archive contains a set of quality flags, which are used to screen the data. Although this

\footnotetext{
${ }^{2}$ It should be noted that these classes are only used to assign radiative transfer coefficients in the LAI retrieval algorithm. Therefore, the MODIS LAI product does not assume any in-class homogeneity. See Fensholt et al. (2004) for an evaluation of the datasets.

${ }^{3}$ COSMO-I7 is the ARPA-SIM implementation of the COSMO model.
} 
greatly reduces the number of pixels usable to construct the dataset, it is found necessary to apply a quality-check protocol to guarantee reliable LAI estimation.

Using 6 years of data (2001-06) an annual climatology has been constructed. This is achieved by calculating an average LAI map for each MODIS day. For each pixel, only measurements that pass the quality check are used. In particular, only those observations are included in the average that are processed using the main algorithm, are classified as cloud-free, and created under all aerosol conditions. This leads to regions where the climatology is generated out of less than six values, or it is not created at all (leaving pixels with missing data in the dataset). Although statistically questionable, the averaging with less than six data points is accepted as this climatology is only employed to smooth the real-time MODIS data and to remove presumably spurious outliers. Missing data are treated by first employing a linear interpolation in time if there are valid observations for more than half of the year's MODIS days. The remaining holes are filled by using the modeled LAI values from the LCB approach. The climatology is updated annually.

In the MOD dataset, the actual-day variability is also ensured by a blending procedure, which uses both the climatological dataset and an up-to-date observation from the nearest MODIS day. LAI maps are downloaded in real time and are given a weight between 1 and 0 when compared to their climatology, according to their quality flags. Thus, the MODIS LAI dataset in the operational implementation is always updated with the most recent observations as long as they are of appropriate accuracy. The blending procedure guarantees that each dataset is complete and has no missing values.

\section{b. Comparison between datasets}

\section{1) Spatial Distribution}

Because the CORINE project had to describe complex land patterns using only a few categories, the result is that CORINE class descriptions can be quite broad. For example, the CORINE definition given for "complex cultivation pattern" is "juxtaposition of small parcels of diverse annual crops, pasture and/or permanent crops" (Commission of the European Communities 1995), which suggests the coexistence of areas with very diverse vegetation characteristics. For this land cover class, the Ecoclimap project provides an LAI estimation, which is a weighted mean of the LAIs present in the cells. The result is that very little LAI variability can be expected in the LCB dataset over Italy.

Figure 1 shows LAI distributions predicted by the MOD dataset and aggregated over CORINE land classes. Two days are considered: day 24 (24 January; the

\section{Broad-leaved forest}

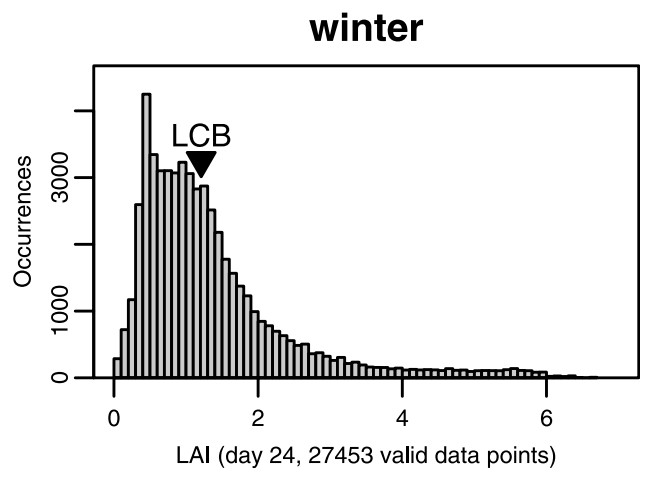

summer

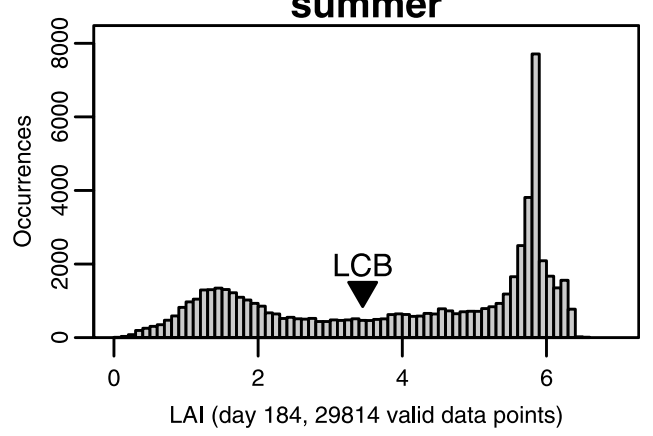

Complex cultivation patterns

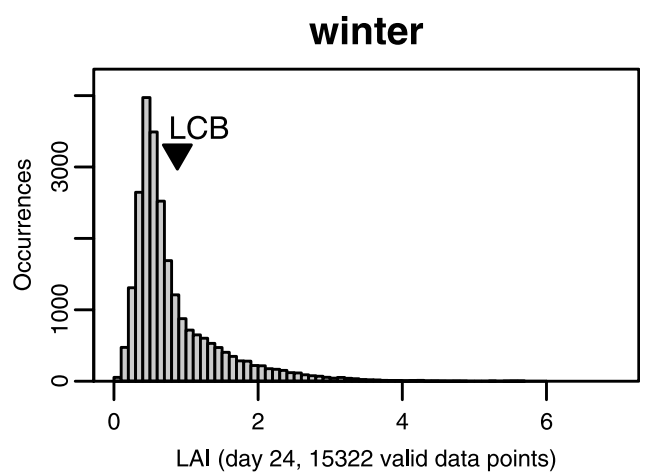

summer

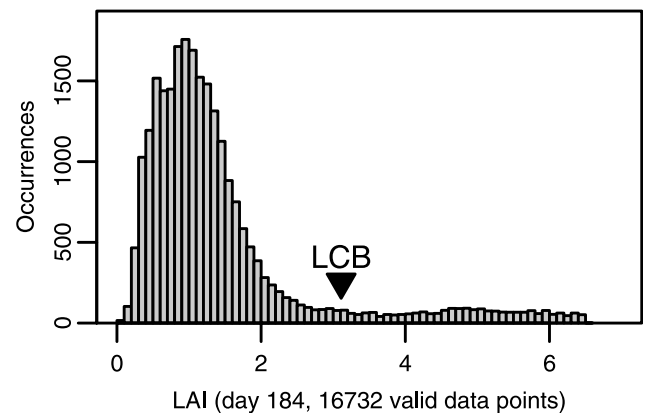

FIG. 1. LAI PDF from the MOD dataset. The PDFs are aggregated over two CORINE land cover classes. Two example days are considered for each class: $24 \mathrm{Jan}$ (winter case) during the plant resting period and $3 \mathrm{Jul}$ (summer case) during the plant vegetative period. The predicted LCB-LAI values are marked by triangles. 
"winter" case) during plant resting, which is representative of a minimum in LAI evolution, and day 184 (3 July; the "summer" case) during the plant vegetative period when maximum LAI values are expected. As expected, the MOD dataset clearly highlights that LAI values are neither homogeneous inside a CORINE class nor normally distributed, which could justify the statistical use of representative mean LAI values as it is done in the LCB approach.

Moreover, in-class homogeneity can change passing from summer to winter months as demonstrated by the "complex cultivation patterns" class, which, although it shows a more homogeneous distribution of LAI values in winter, it fails to be homogeneous in summer. There, in summer, the LCB-LAI value represents an overestimate for the majority of the pixels analyzed. As a consequence the LCB approach is likely to also overestimate latent heat flux prediction during model integrations.

\section{2) ANNUAL COURSE MODULATION}

LCB and MOD show very different trends in their annual cycle. The time evolution of LCB-LAI is calculated using Eq. (1) everywhere over the globe. At Italian latitudes, vegetation resting (i.e., minimum LAI) is expected between mid-November to mid-February, whereas the full vegetative period occurs from the end of June to the end of August. The typical Mediterranean climate strongly influences the LAI development over the year with southern regions being afflicted by desiccation in the warmest periods. These events are likely to influence LAI values and significant reductions can be expected in (late) summer months.

The climate, however, is generally favorable for agriculture. With its mild winters, the farmers are able to bring in more than one harvest over the year. This peculiar agricultural cycle should produce a different annual modulation, at least in those classes containing cultivated agricultural areas. The LAI annual cycle for the MOD dataset averaged over a selection of CORINE land cover classes is shown in combination with the predicted modulation of the LCB approach (Fig. 2).

An example discrepancy between the MOD and LCB approaches can be seen in the CORINE class named "permanently irrigated land." The MOD dataset is able to capture the complex LAI change over the year resulting from a sequence of sowings and harvestings, which occur around days 150,240, and 320, whereas the fix modulation of the LCB approach misses it completely. The "sclerophyllous vegetation" class (Fig. 2) refers to wild type of vegetation characterized by hard, leathery, evergreen foliage that is specially adapted to prevent moisture loss and is characteristic of Mediterranean areas. This kind of vegetation has its maximum lush in
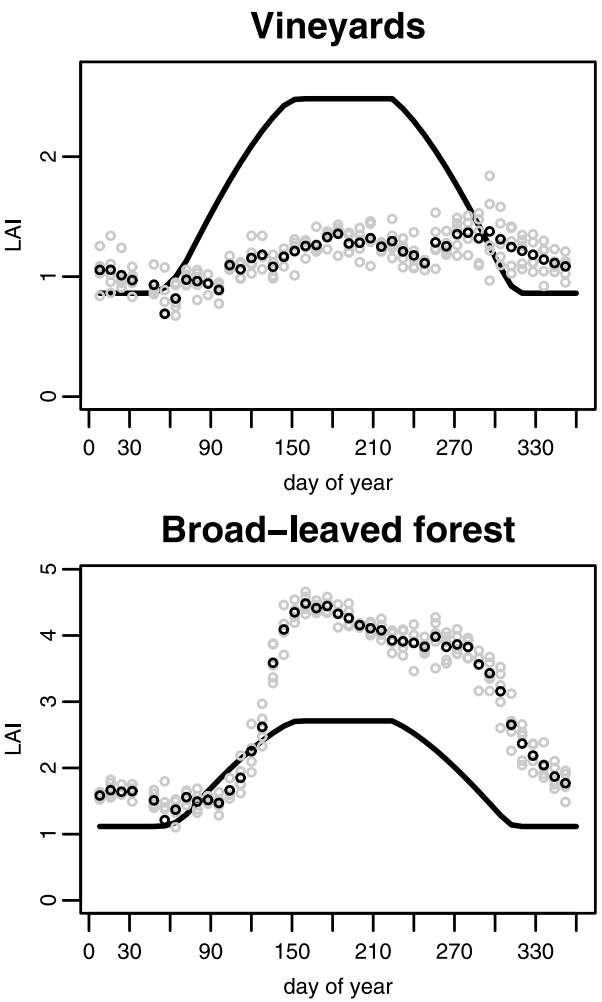

Sclerophyllous vegetation

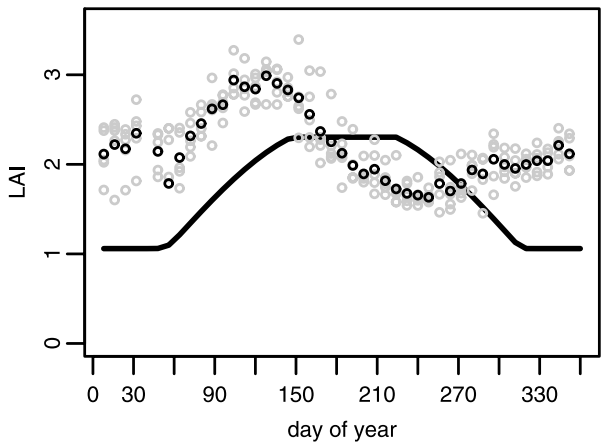

Permanently irrigated land

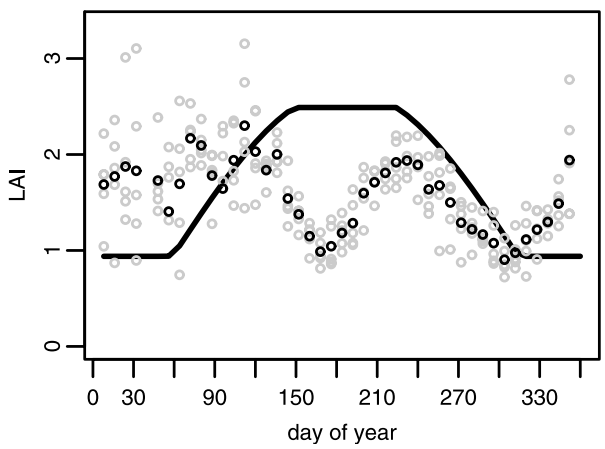

FIG. 2. LAI annual cycle for the MOD and LCB datasets averaged over the CORINE land cover classes. The black line represents the LCB annual modulation. Gray points are MOD values in one year. Black points depict the mean over the 6 years used to construct the MOD climatology. 
late spring and is often affected by desiccation starting in early summer, which is correctly predicted by the MOD database. Again, the LCB fails to correctly shorten the vegetative period of these plants. The vegetation period for "broad-leaved forest" is too short and its intraannual variability is badly underestimated. The "vineyards" class shows little to no annual cycle at all in MOD, which leads to a serious overestimation of LAI by the LCB approach in summer. In general, the LCB approach can neither capture the annual vegetative cycle, even for widespread classes like broad-leaved forest or sclerophyllous vegetation, nor reasonably capture LAI minimum and maximum for these classes.

\section{c. Impact on predicted surface fluxes}

LAI changes can variate surface fluxes, as predicted by the COSMO-I7 model. Differences between the FIX and LCB experiments quantify the impact of introducing a "mean" (averaged over CORINE classes) LAI variability across the COSMO domain, whereas differences between MOD and LCB datasets can be regarded as a metric of accounting for LAI variance inside a given class. To quantify the impact on surface fluxes of different LAI specification, two cases have been selected; a winter case (19 January 2006) marked by a high pressure system over the Tyrrhenian Sea and localized fog over the Po Valley and a summer (8 July 2007) case characterized by strong convective instabilities in the northeast part of the COSMO-I7 domain. All datasets are reported on the 7-km rotated grid of the COSMO-I7 model. An inconsistency exists in LAI definition between COSMOI7 (leaf area per vegetated part of the grid cell) and the LAI definition used to construct the datasets (leaf area per grid cell). Because MODIS does not provide a consistent/validated $f_{\text {veg }}$ datatset, the vegetated fraction prescribed by the Ecoclimap project over CORINE classes is used to rescale all LAI datasets. This could cause unrealistic inhibitions of evaporation on those grid cells with null LAI and unitary vegetation fraction because neither the contribution from the bare soil nor from the vegetation would be allowed. An additional check therefore guarantees that pixels with LAI null also have vegetation fraction null and vice versa. Over the COSMO-I7 domain, these situations account for less than $0.01 \%$.

Figures 3 and 4 show the LAI maps from FIX, LCB, and MOD datasets for the two days under study. LCB predicts larger LAI values than MOD over plains and smaller values over mountains. Estimated LCB LAI values larger than 2 in summer and 1 in winter are a rather implausible assumption over plains, considering the high proportion of coverage of the Italian plains by constantly trimmed deciduous fruit plants (Ministero
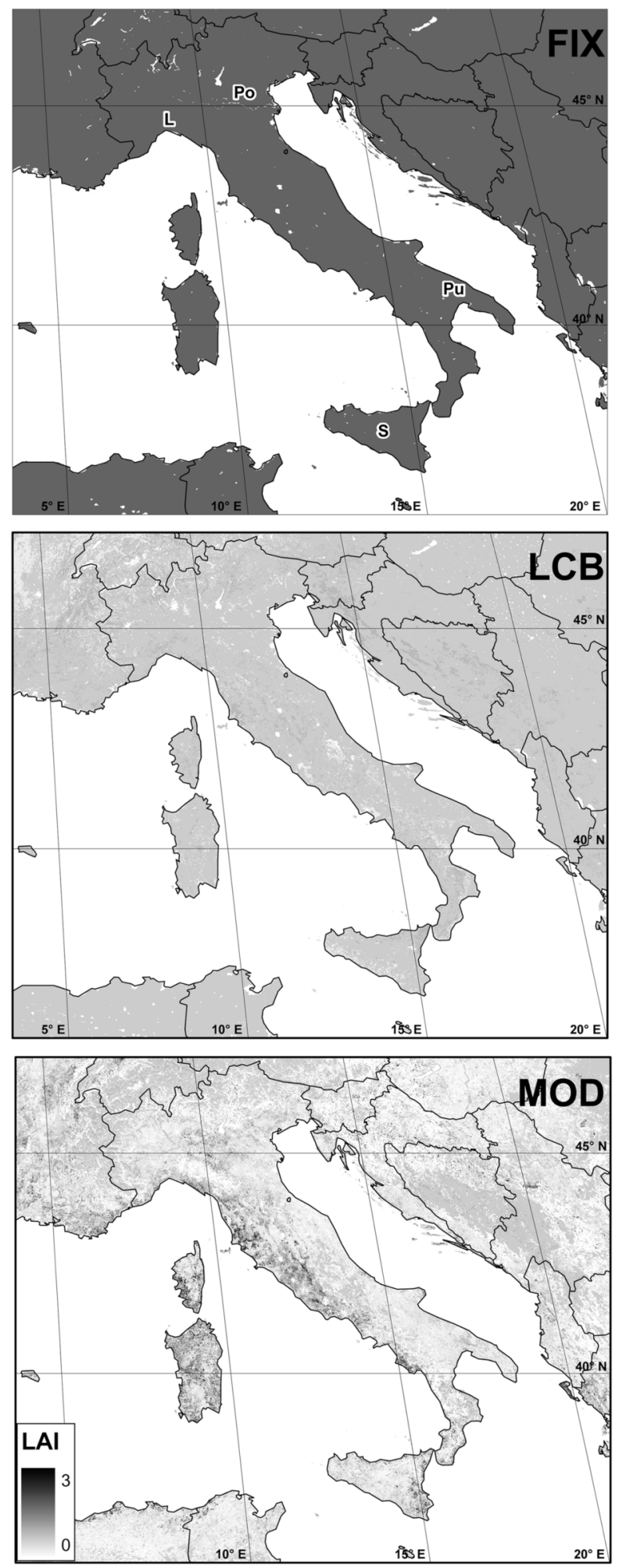

FIG. 3. LAI maps for winter day example (19 Jan 2006) using the (top) FIX, (middle) LCB, and (bottom) MOD databases. Regions mentioned in the text are marked: Po Valley (denoted "Po"), Ligurian coast (denoted "L"), Puglia region (denoted "Pu"), and the island of Sicily (denoted "S"). See text for further details. 

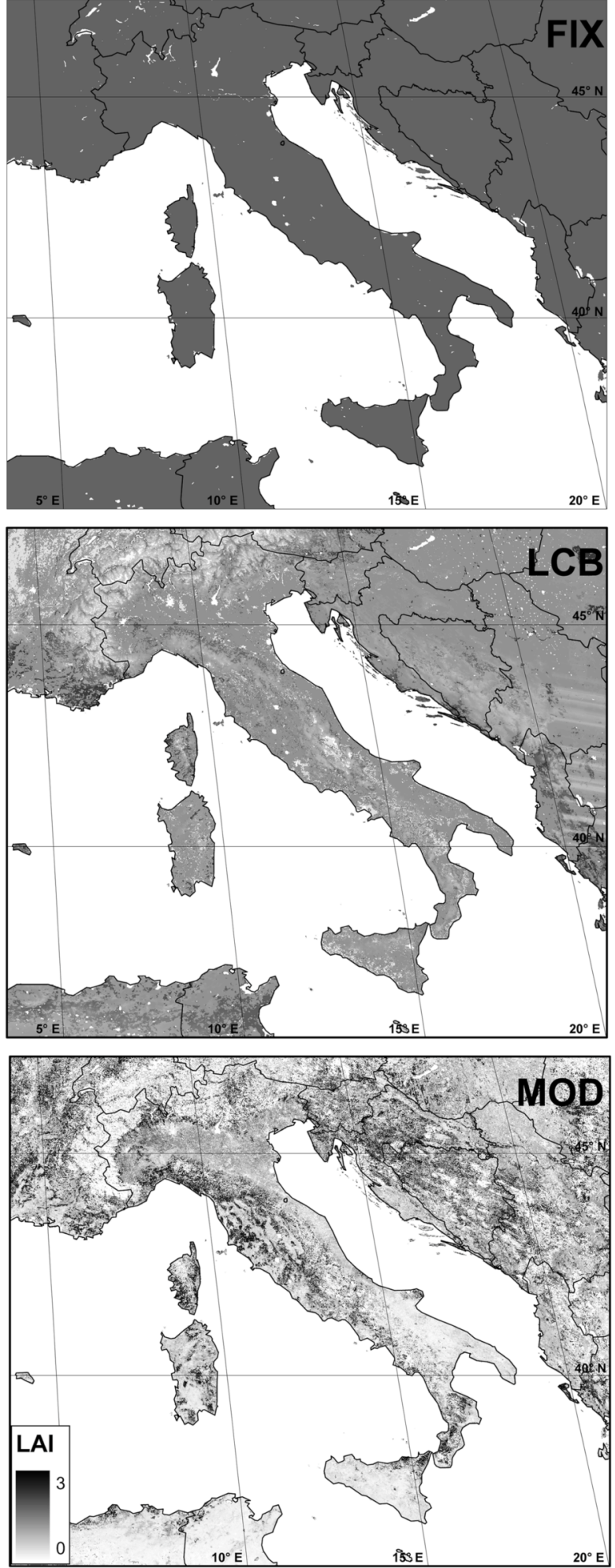

FIG. 4. LAI maps for summer day example (8 Jul 2007) using the (top) FIX, (middle) LCB, and (bottom) MOD databases. See text for details.
dell'Agricoltura e delle Foreste 1985; Stöckli and Vidale 2004). Obviously, the MOD dataset shows a larger variability, and it is able, particularly in the summer case, to capture the expected small LAI values in the Po Valley, which occur after the harvesting, and the high values along the narrow forest of the Ligurian coast. In addiction, the MOD dataset captures the expected small LAI values in most parts of the Puglia and Sicily regions, which, although occupied by cultivated fields, are afflicted by the warm (desiccating) climate of southern Italy. For the winter day, the MOD dataset clearly identifies the western coast of Italy as lusher because of the predominantly eastward atmospheric circulation in this area, which results in additional precipitation when compared to the eastern coast.

Surface fluxes are calculated using the surfacevegetation model TERRA incorporated into the regional forecast model COSMO (Schrodin and Heise 2001). The scheme calculates sensible heat flux $H$, latent heat flux LE, and momentum flux by using the transfer coefficients for momentum and heat derived from Monin-Obukhov similarity theory with the iterative method of Louis (1979):

$$
\begin{aligned}
H & =-c_{p} \rho u_{*} T_{*} \text { and } \\
\mathrm{LE} & =-\lambda \rho u_{*} q_{*},
\end{aligned}
$$

where $\rho$ is the air density, $c_{p}$ is the specific heat of air at constant pressure, $\lambda$ is the latent heat of evaporation, and $u_{*}$ is the friction velocity. The terms $T_{*}$ and $q_{*}$ are the surface flux of temperature and water vapor, respectively, and are defined as

$$
\begin{aligned}
& T_{*}=-C_{h}^{d}\left|v_{h}\right|\left(\theta \pi_{\mathrm{sfc}}-T_{\mathrm{sfc}}\right) \quad \text { and } \\
& q_{*}=C_{q}^{d}\left|v_{h}\right|\left(q^{v}-q_{\mathrm{sfc}}^{v}\right),
\end{aligned}
$$

where $C_{h}^{d}$ and $C_{q}^{d}$ are the bulk aerodynamic transfer coefficients for turbulent heat and moisture exchange at the surface, respectively; $\left|v_{h}\right|$ is the absolute wind speed at the same level; and $\theta$ and $\pi_{\text {sfc }}$ are the potential temperature at the lowest grid level and the scaled pressure at the ground, respectively. Finally, $\theta \pi_{\mathrm{sfc}}-T_{\mathrm{sfc}}$ and $q^{v}-q_{\mathrm{sfc}}^{v}$ represent the gradient of temperature and specific humidity between the ground and the first atmospheric levels. The values of $T_{\mathrm{scc}}$ and $q_{\mathrm{sfc}}^{v}$ are predicted by the land scheme, assuming that the contributions to the heat and moisture fluxes are given by evaporation from bare soil, snow store, and the uppermost soil store, in addition to the transpiration of the vegetation. To determine the evaporation from bare soil and the transpiration by plants, the model uses the BATS scheme of Dickinson (1986). 
For all soil types (except rocks and ice) the transpiration by plants is parameterized as

$T_{r}=f_{\mathrm{veg}}\left(1-f_{i}\right)\left(1-f_{\text {snow }}\right) E_{\mathrm{pot}}\left(T_{\mathrm{sfc}}\right) r_{a}\left(r_{a}+r_{f}\right)^{-1}$,

where $r_{f}$ is the resistance for water vapor transport from the foliage to the canopy air (foliage resistance); $r_{a}$ is the resistance of water vapor transport between the canopy and the atmosphere (aerodynamic resistance); and $f_{i}$ and $f_{\text {snow }}$ are the partial coverages of the land surface by interception water and snow, respectively. The foilage resistance,

$$
r_{f}^{-1}=r^{\prime} f_{\mathrm{LAI}} r_{\mathrm{la}}^{-1},
$$

consists of $r^{\prime}$, a stomatal resistance function that depends on various factors that influence the actual plant transpiration; currently, these are radiation, soil water content, ambient temperature, and specific humidity of the ambient air (Doms et al. 2004). The term $r_{\mathrm{la}}$ is a resistance term depending on friction velocity, and $f_{\text {LAI }}$ is the leaf area index. By determining the foliage resistance, the LAI can influence the release of water vapor to the atmosphere and thereby the Bowen ratio. It can also be seen from the description of $r_{\text {la }}$ that LAI is not the only factor influencing the partitioning. Yang and Dickinson (1995) give a detailed description of the BATS scheme, and an elaborated sensitivity study of the scheme regarding the ecological parameters as well as toward meteorology can be found in Henderson-Sellers (1993).

In the Agenzia Regionale Prevenzione e Ambiente dell'Emilia-Romagna Servizio IdroMeteoClima (ARPASIMC) implementation of COSMO (COSMO-I7), the horizontal model domain is set to cover Italy, the major part of the Mediterranean Sea, and the Alpine region (see e.g., Fig. 3 for the operational domain specification). The grid size is $7 \mathrm{~km}$ and there are 40 levels in the vertical between the surface and the top of the troposphere at around $30 \mathrm{hPa}$. Hourly boundary conditions are provided by the European Centre for Medium-Range Weather Forecasts (ECMWF) global model Integrated Forecast System (IFS; Gregory et al. 2000).

Figure 5 shows histograms of sensible and latent heat flux differences between the three datasets for the two days under study at $12 \mathrm{~h}$ forecast time. In the winter case the three datasets produce comparable surface flux predictions and variability inside the domain is minimal due to the overall small mean LAI values. In this case $98 \%$ of the domain points have differences less than $3 \mathrm{~W} \mathrm{~m}^{-2}$. Different are the results for the summer case where larger differences both in sensible and latent heat fluxes are underlined by the MOD-LCB histogram. If LAI variance over land cover classes is taken into ac- count (i.e., MOD dataset), flux predictions vary accordingly with a decrease of latent heat and an increase of sensible heat over large areas (Fig. 5, top). Differences in fluxes are in agreement with the overall smaller LAI prediction (smaller evapotranspiration) of the MODLAI with respect to the LCB-LAI. Locally, the effect can be as large as $75 \mathrm{~W} \mathrm{~m}^{-2}$, a value comparable to flux differences found by Kurkowski et al. (2003) through variations in vegetation fraction. Interestingly, the impact of using the LCB dataset compared to an average constant value (FIX-LAI) is almost negligible if we exclude some localized spots, mostly localized over the Alps (not shown). Therefore, this comparison highlights the limitation of reducing LAI estimation to a few land cover classes, which suppresses the LAI variability. However, even if MOD estimation is in better agreement with the known seasonal cycle of Mediterranean ecosystems, this is not a guarantee that the corresponding surface fluxes are more accurate. Compensating errors due, for example, to inexact soil moisture could nullify the expected improvements. Therefore, in the following sections, a detailed validation of the LAI datasets is performed by means of forecast versus analysis scores and comparison with observations.

\section{Validation of the LAI dataset}

The direct validation of FIX, LCB, and MOD datasets would require observations of LAI, which are rare and not representative of a 7-km model grid box. The assessment of the three datasets is necessarily conducted indirectly by means of forecast skills and by comparison with in situ observations. The 2-m dry and dewpoint temperatures from the synoptic network and surface fluxes collected during the CarboEurope campaigns are employed (i.e., the surface parameters that are mostly affected by LAI choices). To maximize the impact, a summer period of 30 days has been chosen starting from 1 June 2005. Runs are initialized at 0000 UTC and last $72 \mathrm{~h}$. Data assimilation is performed by using a nudging scheme (Schraff and Hess 2003) for the $24 \mathrm{~h}$ before the nominal forecast date. According to availability, observations from the standard synoptic networks (mostly SYNOP, AIREP, and TEMP) are used during the analysis integration. The SYNOP network provides model prognostic variables such as temperature, humidity, wind, and pressure at synoptic times over land surfaces at a standard height of $2 \mathrm{~m}$ above ground level. Nine radiosounding stations located over the integration domain form the TEMP network. These measurements provide wind, temperature, humidity, and pressure vertical soundings, mostly at two times per day. Finally, further observations are recorded from sensors mounted 
differences in latent heat flux 08jul2007 12:00 UTC

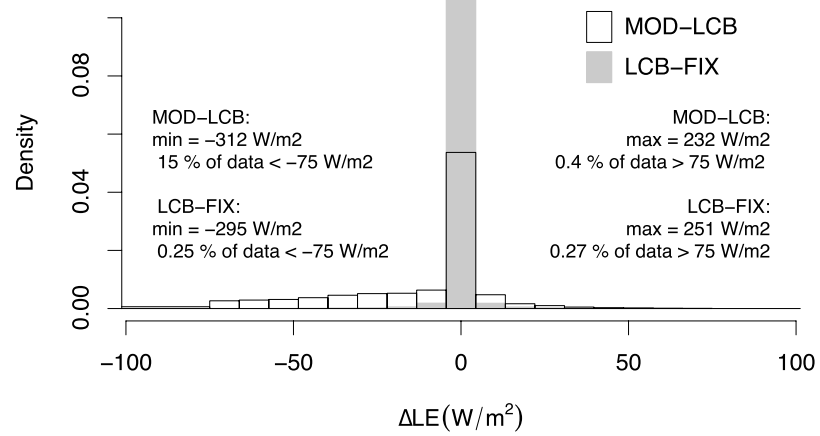

differences in latent heat flux 19jan2006 12:00 UTC

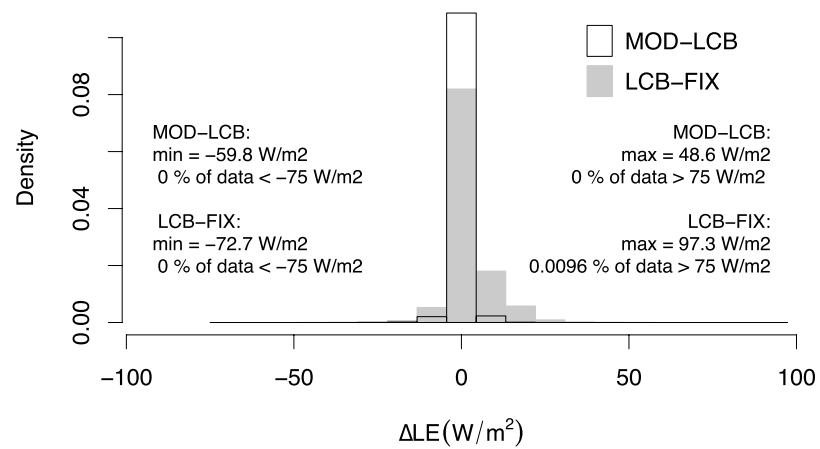

differences in sensible heat flux 08jul2007 12:00 UTC

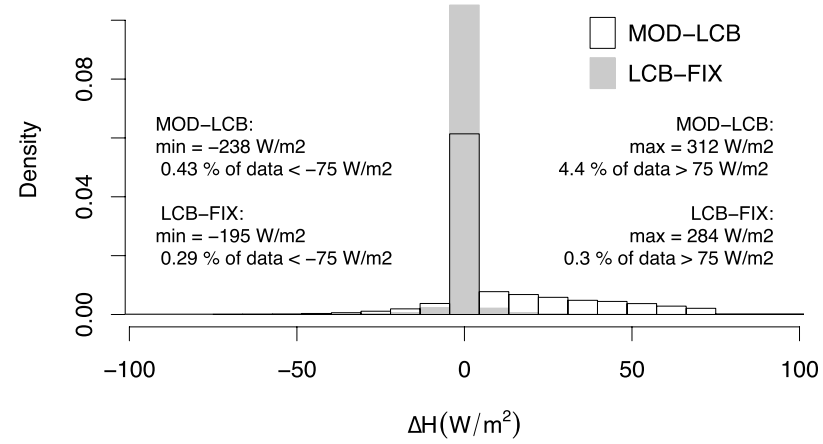

differences in sensible heat flux 19jan2006 12:00 UTC

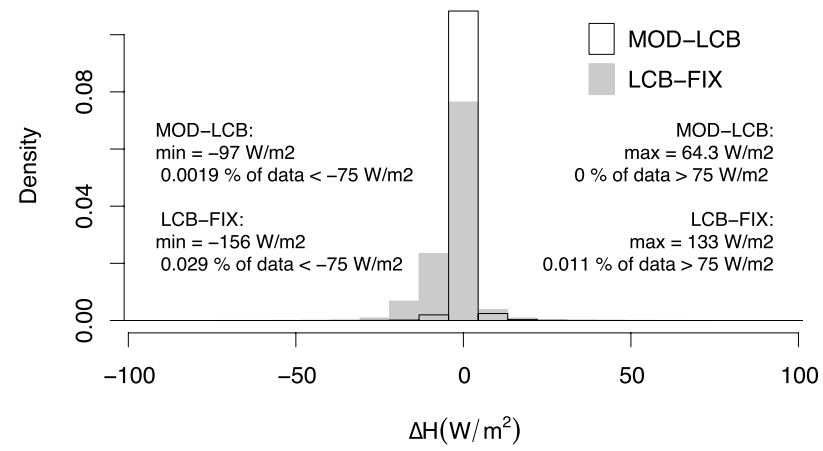

FIG. 5. Histograms of sensible and latent heat flux differences among the three datasets for the two days under study at 12-h forecast time.

on commercial airplanes (AIREP), which are therefore mostly only available along commercial routes. Because around 50000 observations are processed at each cycle, the resulting analysis can be considered to a certain extent as a good proxy of reality, at least for variables that are directly observed, such as temperature and humidity.

\section{a. Forecast skills}

Forecast errors (forecast minus analysis) differences for 2-m temperature $T_{2 \mathrm{~m}}$ are shown in Fig. 6. At $+36 \mathrm{~h}$ forecast, the mean error reduction/increase when passing from MOD to LCB and from LCB to the FIX database is reported. Each forecast is compared with its own analysis to ensure a fair assessment of the bias. The value of $T_{2 \mathrm{~m}}$ is directly calculated from the ground temperature $T_{\mathrm{sfc}}$ and the temperature of the first atmospheric level, given the stability state of the atmosphere provided by the planetary boundary layer (PBL) scheme. It has to be noted that even if this model diagnostic variable is directly influenced by the evapotranspiration of plants and should therefore benefit from a better LAI specification, $T_{\text {sfc }}$ is also strongly determined by the soil humidity, which is largely unknown. It is therefore possible that improvements in forecast skills could be weakened by compensating errors when a comparison with observations is performed. Nevertheless, even if these errors cannot be used to accurately quantify the absolute model error on surface parameters, it can serve as a diagnostic for the sensitivity of the PBL scheme to the LAI.

Different LAI datasets have also an impact on upperair variables (not shown). In particular, a significant reduction of forecast-analysis error is achieved by the MOD dataset at $850 \mathrm{hPa}$ for both the temperature and humidity fields. Again, the use of the LCB approach does not produce significant differences when compared to a constant average LAI.

\section{b. Comparison with observations}

Analysis and forecasts can be affected by the same systematic model errors, and thus a direct comparison to observations is also made. Figure 7 and 8 show screenlevel dry and wet temperature biases at a forecast time of $+36 \mathrm{~h}$ (noon). Comparisons are performed against synoptic observing stations, which are split into mountain sites (above $500 \mathrm{~m}$ ) and valley sites (below $500 \mathrm{~m}$ ). The three LAI datasets have the same impact on the minimum temperature bias, whereas the prediction of 


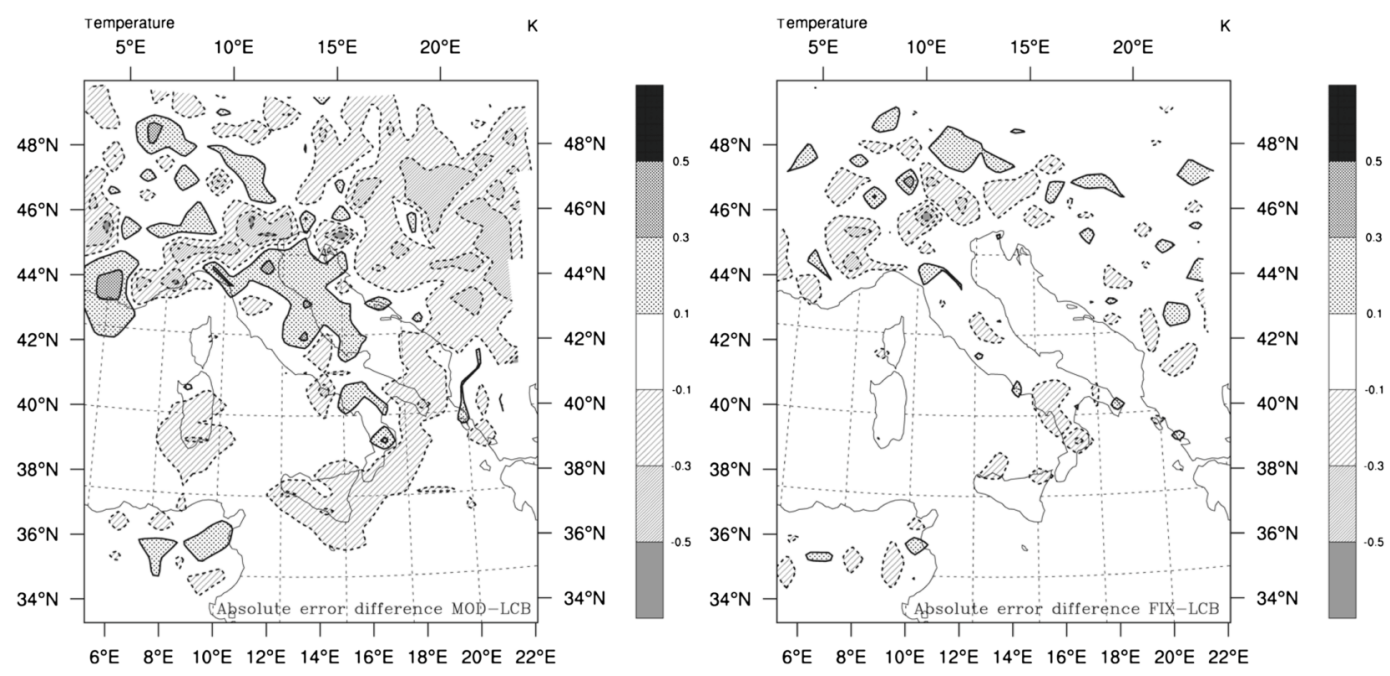

FIG. 6. The +36 -h forecast error differences for 2-m dry temperature (left) between MOD and LCB and (right) between FIX and LCB.

maximum temperatures is worsened by the use of the MOD approach. The variables $T_{2 \mathrm{~m}}$ and $\mathrm{Td}_{2 \mathrm{~m}}$ are diagnostic and their calculation through the similarity theory (Stull 1988) involves many boundary layer variables, which can be highly uncertain, giving rise to compensating errors. In the next section, the impact of LAI specification on surface fluxes will be also analyzed. Impact of the MOD LAI on the dewpoint temperatures is significantly lower than on the dry temperatures. Mountain stations possess larger biases in dry temperature, probably because of inadequacies of the current assimilation scheme to describe rugged terrain.
Sensible and latent heat fluxes predicted by the COSMO model during the first $24 \mathrm{~h}$ of forecast integration are compared with observed data, which were collected in the framework of the EU-funded research project CarboEurope Integrated Project (CarboEurope-IP). This activity has the main aim of quantifying the relationship between carbon fluxes and vegetation characteristics. Therefore, great attention has been posed to locate observing stations over different land use/cover types. Measurements (available online at http://www.carboeurope.org) are recorded every half hour since 2004 on more than 100 eddy flux stations over
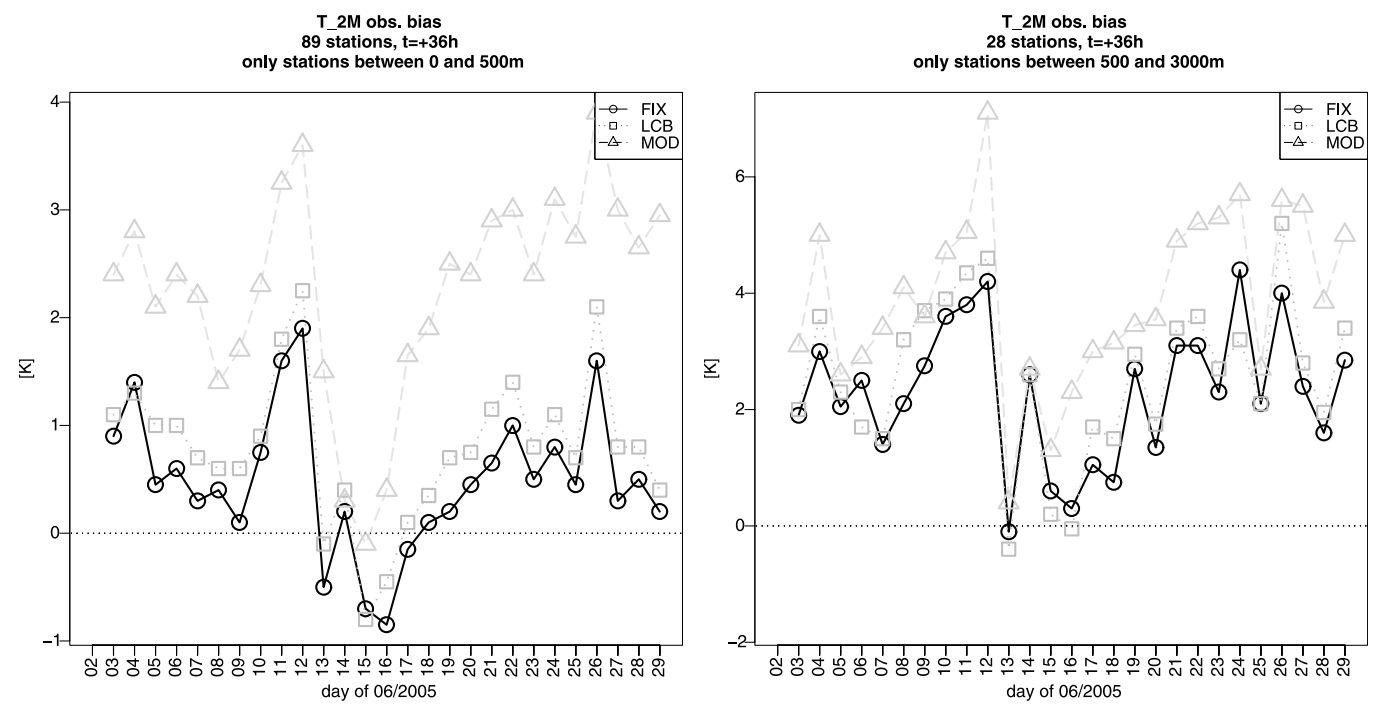

FIG. 7. Screen-level dry temperature biases at $+36-\mathrm{h}$ (noon) forecast time. Around 100 synoptic observing stations are used, which cover the Italian territory. The available observations are split into mountain stations (above $500 \mathrm{~m}$ ) and valley stations (below $500 \mathrm{~m}$ ). 

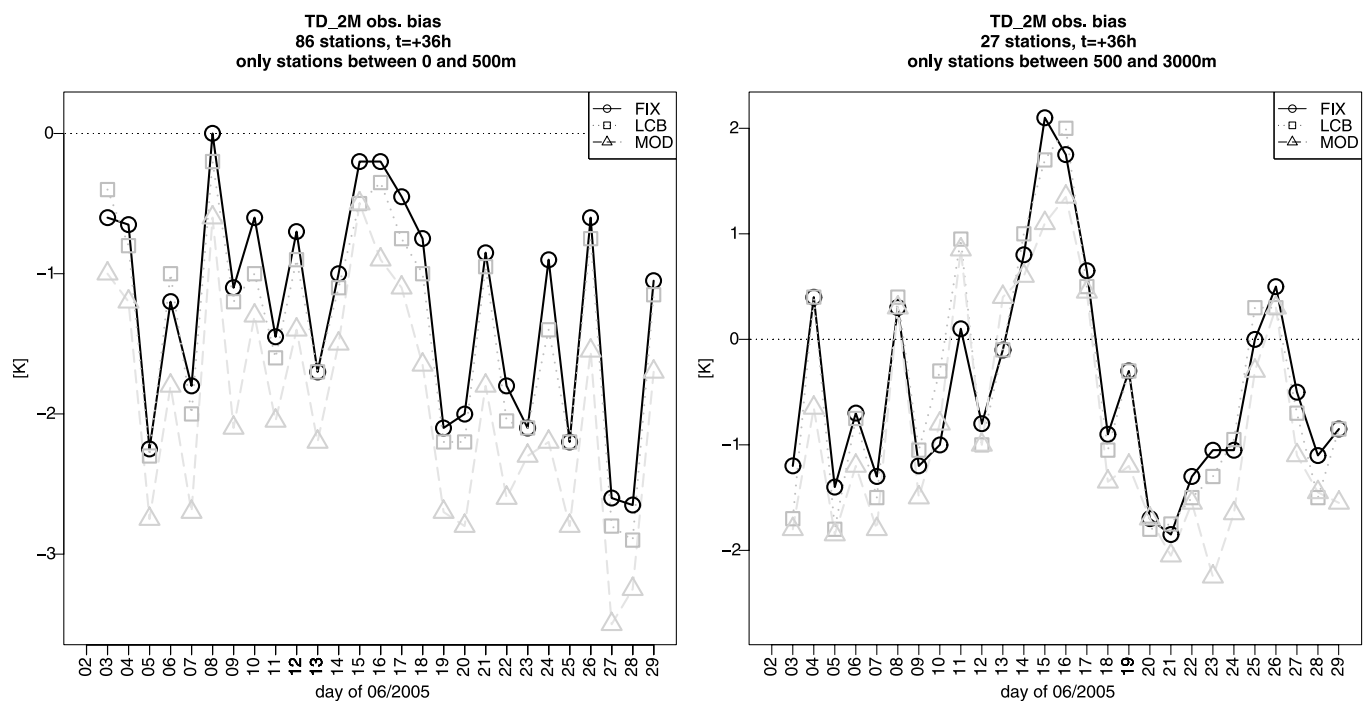

FIG. 8. As in Fig. 7, but for dewpoint temperature.

Europe. The collected dataset potentially possesses a good representativity of fluxes over different ecosystem types. The location and the vegetation characteristic of the stations that fall into the COSMO-I7 domain and were active during the validation period (June 2005) are reported in Table 2.

Figure 9 shows the comparisons of the predicted latent and sensible heat fluxes for two example sites of the six CarboEurope stations analyzed. Three-hourly model data are compared with observed data averaged over the same period. The two data clusters for nighttime (0000 UTC) and daytime (1200 UTC) observations are clearly visible. COSMO-I7 systematically underestimates latent heat fluxes (average of $-30 \%$ ) and overestimate sensible heat fluxes regardless of the site position (average of $+40 \%$ ). The consequence of this is an excessively turbulent boundary layer, which inhibits the formation of low-level inversions. This is a known limitation of the COSMO model (Jongen and Bonafè 2005). The maximum relative difference in the total flux at the surface (i.e., $L_{E}+H$ ) is $10 \%$ (Table 3 ). Nevertheless, the soil and vegetation scheme fails to correctly partition the latent and sensible fluxes, probably because of an underestimation of soil moisture resulting in an underestimation of the Bowen ratio. For each of the three experiments, the $a$ and $b$ coefficients of the best linear fit (forecast $=a \times$ observed $+b$ ) and the Pearson's correlation coefficients $R^{2}$ are reported. Especially for latent heat fluxes, there is little correlation between forecast and observations for all experiments (small and similar $a$ values). The use of different datasets has the overall effect of offsetting the latent heat estimation without generally improving its variability as demonstrated by the differences in the $b$ coefficients. This strongly suggests that other factors are limiting the ability of the soil scheme to obtain correct latent heat fluxes. Because estimations of sensible heat fluxes are generally of better quality, the reason for this lack of improvement is most likely found in the soil moisture initialization.

Table 3 summarizes the surface energy budget at the surface over the six CarboEurope sites. Averages are performed for the whole day during daytime (between 0900 and 1800 UTC) and nighttime (between 2100 and 0600 UTC). Hours at dusk and at dawn are excluded from the average. LCB and FIX datasets produce very similar flux estimations, both in terms of distribution and midday

TABLE 2. CarboEurope-IP sites used for the comparison with the COSMO-I7 model.

\begin{tabular}{|c|c|c|c|c|c|}
\hline Code & Name & Lat & Lon & Alt (m) & Ecosystem type \\
\hline IT-Amp & Amplero & $41^{\circ} 54^{\prime} 14^{\prime \prime}$ & $13^{\circ} 36^{\prime} 18^{\prime \prime}$ & 884 & grassland \\
\hline IT-BCi & BorgoCioffi & $40^{\circ} 31^{\prime} 25^{\prime \prime}$ & $14^{\circ} 57^{\prime} 26^{\prime \prime}$ & 20 & cropland \\
\hline IT-Cpz & Castelporziano & $41^{\circ} 42^{\prime} 18^{\prime \prime}$ & $12^{\circ} 22^{\prime} 33^{\prime \prime}$ & 68 & forest \\
\hline IT-Ro1 & Roccarespampani 1 & $42^{\circ} 24^{\prime} 29^{\prime \prime}$ & $11^{\circ} 55^{\prime} 48^{\prime \prime}$ & 234 & oak \\
\hline IT-Ro2 & Roccarespampani 2 & $42^{\circ} 23^{\prime} 24^{\prime \prime}$ & $11^{\circ} 55^{\prime} 15^{\prime \prime}$ & 223 & oak \\
\hline IT-Tol & Tolfa & $42^{\circ} 11^{\prime} 22^{\prime \prime}$ & $11^{\circ} 55^{\prime} 17^{\prime \prime}$ & 473 & shrub \\
\hline
\end{tabular}



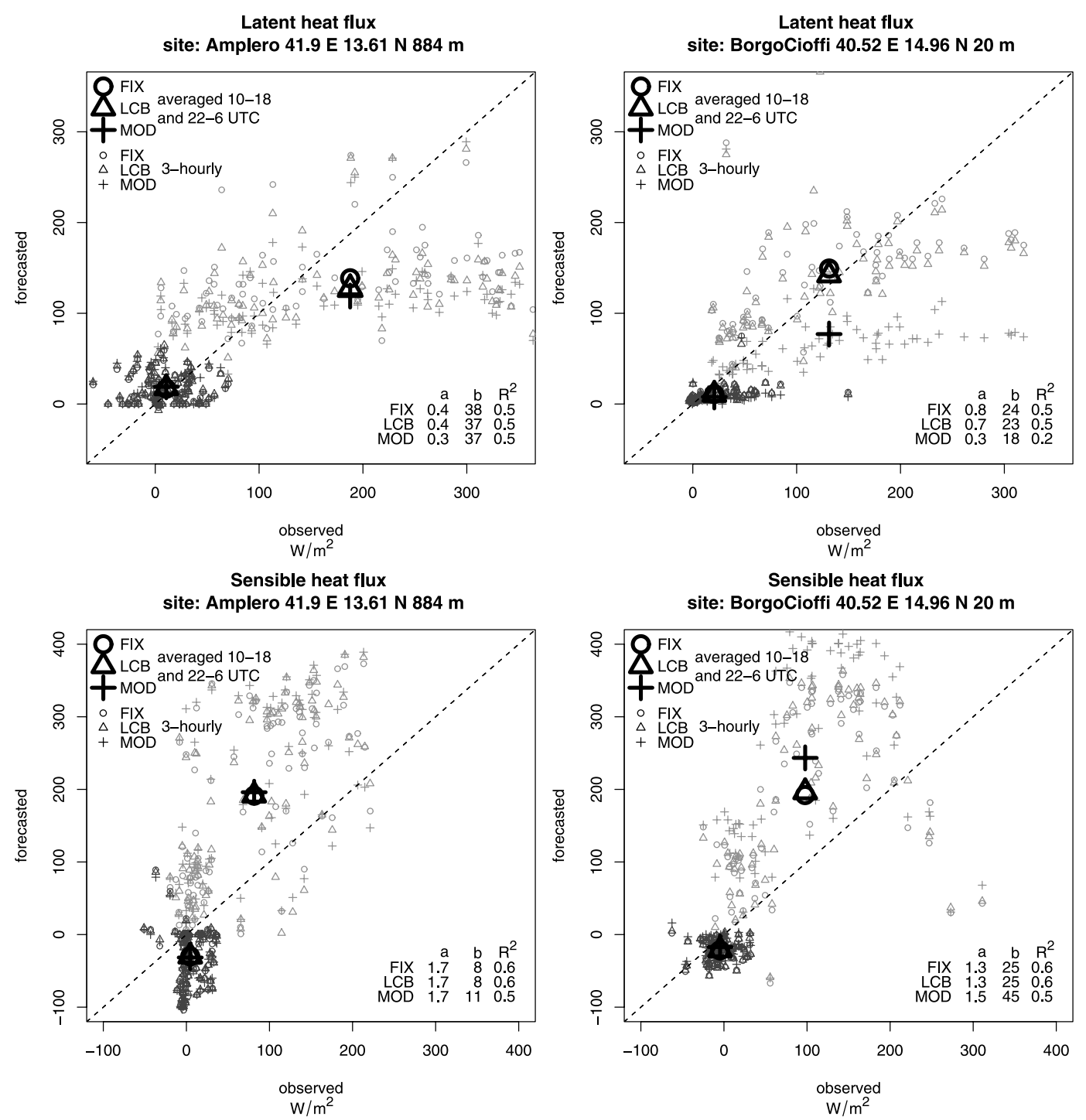

FIG. 9. Observational biases of turbulent fluxes. Dark symbols are used for nighttime observations (2200-0600 UTC), and light symbols are used for daytime observations (1000-1800 UTC). Oversized markers are mean biases of each approach. The $a$ and $b$ coefficients for the best linear fit (forecast $=a \times$ observed $+b$ ) are also reported. The term $R^{2}$ is the Pearson's correlation coefficient.

average fluxes (represented by the oversized markers in Fig. 9), confirming that there is no substantial difference between using a land cover approach with respect to an overall fix LAI, at least in regional modeling (see also Table 4 for LAI values at the CarboEurope sites from the 3 datasets). Fluxes forecast by MOD are only very similar to those predicted by FIX and LCB in two sites (sites ITAmp and IT-Tol). In all other sites, MOD brings a reduction of $L_{E}$ between 20 and $100 \mathrm{~W} \mathrm{~m}^{-2}$ and an increase of $H$ up to $+50 \mathrm{~W} \mathrm{~m}^{-2}$, which is in agreement with the substantial reduction of LAI estimation of this dataset. This produces a deterioration of the already negative latent heat and positive sensible heat biases.
It should be noted that because CarboEurope sites were selected with the analysis of carbon dioxide fluxes of natural origin in mind, they are installed in areas that could be poorly representative of their surroundings. Data derived from sites located in specific plant ecosystems are likely to refer mainly to the vegetated part of the terrain, which could result in an underestimation of the contribution from the bare soil. On average, this can partially explain the model underestimation of latent heat. On the other hand, it is also reasonable that uncertainties on soil moisture and plant cover can play an important role to the final bias [see Godfrey and Stensrud (2008) for an investigation on soil moisture errors in an 
TABLE 3. Energy budget at the 6 CarboEurope-IP sites as estimated using the 3 LAI datasets.

\begin{tabular}{|c|c|c|c|c|c|c|c|c|}
\hline \multirow[b]{2}{*}{ Flux $\left(\mathrm{W} \mathrm{m}^{-2}\right)$} & \multirow[b]{2}{*}{ Time (UTC) } & \multirow[b]{2}{*}{ Expt } & \multicolumn{6}{|c|}{ CarboEurope-IP sites } \\
\hline & & & IT-Amp & IT-BCi & IT-Cpz & IT-Ro1 & IT-Ro2 & IT-Tol \\
\hline \multirow[t]{12}{*}{$L_{E}$} & \multirow[t]{4}{*}{ 0000-0000 } & FIX & 72 & 73 & 43 & 56 & 56 & 16 \\
\hline & & LCB & 68 & 69 & 39 & 55 & 55 & 17 \\
\hline & & MOD & 65 & 38 & 28 & 33 & 33 & 16 \\
\hline & & OBS & 97 & 79 & 48 & 49 & 89 & 82 \\
\hline & \multirow[t]{4}{*}{$1000-1800$} & FIX & 139 & 149 & 89 & 117 & 117 & 31 \\
\hline & & LCB & 128 & 142 & 79 & 116 & 116 & 33 \\
\hline & & MOD & 119 & 77 & 58 & 68 & 68 & 29 \\
\hline & & OBS & 188 & 131 & 87 & 79 & 156 & 133 \\
\hline & \multirow[t]{4}{*}{$2200-0600$} & FIX & 17 & 11 & 5 & 7 & 7 & 5 \\
\hline & & LCB & 18 & 10 & 4 & 7 & 7 & 5 \\
\hline & & MOD & 19 & 8 & 3 & 5 & 5 & 5 \\
\hline & & OBS & 11 & 21 & 9 & 12 & 16 & 23 \\
\hline \multirow[t]{12}{*}{$H$} & \multirow[t]{4}{*}{ 0000-0000 } & FIX & 68 & 70 & 106 & 80 & 80 & 115 \\
\hline & & LCB & 68 & 72 & 109 & 80 & 80 & 114 \\
\hline & & MOD & 69 & 94 & 116 & 97 & 97 & 114 \\
\hline & & OBS & 46 & 47 & 107 & 39 & 13 & 68 \\
\hline & \multirow[t]{4}{*}{$1000-1800$} & FIX & 191 & 192 & 281 & 204 & 204 & 292 \\
\hline & & LCB & 192 & 196 & 285 & 205 & 205 & 290 \\
\hline & & MOD & 196 & 243 & 301 & 240 & 240 & 291 \\
\hline & & OBS & 82 & 98 & 226 & 82 & 30 & 138 \\
\hline & \multirow[t]{4}{*}{$2200-0600$} & FIX & -30 & -22 & -25 & -17 & -17 & -24 \\
\hline & & LCB & -30 & -21 & -24 & -17 & -17 & -24 \\
\hline & & MOD & -32 & -17 & -22 & -13 & -13 & -24 \\
\hline & & OBS & 5 & -5 & -3 & -6 & -11 & -9 \\
\hline \multirow[t]{12}{*}{$L_{E}+H$} & \multirow[t]{4}{*}{ 0000-0000 } & FIX & 140 & 143 & 150 & 136 & 136 & 131 \\
\hline & & LCB & 136 & 141 & 148 & 135 & 135 & 131 \\
\hline & & MOD & 134 & 132 & 144 & 130 & 130 & 129 \\
\hline & & OBS & 143 & 126 & 155 & 88 & 103 & 150 \\
\hline & \multirow[t]{4}{*}{$1000-1800$} & FIX & 330 & 342 & 370 & 321 & 321 & 322 \\
\hline & & LCB & 320 & 338 & 364 & 320 & 320 & 323 \\
\hline & & MOD & 315 & 320 & 358 & 307 & 307 & 321 \\
\hline & & OBS & 269 & 231 & 313 & 161 & 186 & 272 \\
\hline & \multirow[t]{4}{*}{$2200-0600$} & FIX & -13 & -11 & -20 & -11 & -11 & -19 \\
\hline & & $\mathrm{LCB}$ & -12 & -11 & -19 & -10 & -10 & -18 \\
\hline & & MOD & -13 & -9 & -19 & -8 & -8 & -19 \\
\hline & & OBS & 15 & 16 & 6 & 5 & 4 & 13 \\
\hline \multirow[t]{4}{*}{ Bowen ratio } & \multirow[t]{4}{*}{ 0900-1800 } & FIX & 1.4 & 1.3 & 3.2 & 1.7 & 1.7 & 9.4 \\
\hline & & LCB & 1.5 & 1.4 & 3.6 & 1.8 & 1.8 & 8.8 \\
\hline & & MOD & 1.6 & 3.2 & 5.2 & 3.5 & 3.5 & 10.0 \\
\hline & & OBS & 0.4 & 0.7 & 2.6 & 1.0 & 0.2 & 1.0 \\
\hline
\end{tabular}

NWP model]. This hypothesis is reinforced analyzing the measured values of LAI, which are available in two of the six measurement stations (IT-Amp and IT-BCi) and are reported in Table 4. It is striking that even when a correct LAI estimation is provided by one of the datasets (MOD at IT-Amp and LCB at IT-BCi), the forecast of surface heat fluxes is not substantially improved. This confirms that uncertainties in other soil or vegetation variables contribute to the bias in the flux estimation, making the correct prediction of surface fluxes unobtainable by improvements in LAI estimation alone. This supports earlier research done by Collings and Avissar (1994) and Niyogi et al. (1999).

\section{Conclusions}

Correct predictions of surface sensible and latent heat fluxes can help the prediction of mesoscale circulations (Segal et al. 1988), localized convection (Hammer 1970; Segal et al. 1995; Freedman et al. 2001), and boundary layer characteristics (Monteith 1995). Although some detailed land surface models are available for ecological applications, usually at river basin domain sizes (e.g., Simunek et al. 2005; Marletto et al. 2007), global numerical weather prediction models still lack an adequate representation of surface processes. Most of this inaccuracy is due to the unavailability of datasets able to 
TABLE 4. Available LAI measurements at selected CarboEurope sites and the corresponding estimations using the three LAI datasets.

\begin{tabular}{lccccc}
\hline \hline Code & FIX & LCB & MOD & OBS & Obs period \\
\hline IT-Amp & 3.00 & 2.26 & 1.42 & 1.43 & Avg Jun 2004 \\
IT-BCi & 3.00 & 2.76 & 0.89 & 2.7 & Avg Jun 2005 \\
IT-Cpz & 3.00 & 2.64 & 1.69 & - & - \\
IT-Ro1 & 3.00 & 2.92 & 1.44 & - & - \\
IT-Ro2 & 3.00 & 2.92 & 1.44 & - & - \\
IT-Tol & 3.00 & 3.05 & 2.99 & - & - \\
\hline
\end{tabular}

represent ground characteristics at the spatial and temporal resolution needed for global operational purposes. The general attitude is therefore to use many of the surface parameters as tuning parameters to adjust, for example, the prediction of screen-level diagnostics (Mahfouf 1991; Hess 2001). Obviously, although this can be a suitable first-order approach for short-range forecast, it becomes unacceptable if long integration climate runs or hydrological applications are requested.

The availability of satellite products can improve the temporal and spatial coverage of surface input data needed to land surface schemes and provides valuable information, which can replace this tuning exercise with a more physically based strategy. Using the COSMO limited-area forecast model, the sensitivity of regional predictions to leaf area index assumptions has been investigated over the Italian peninsula. Three different approaches were compared: a space- and time-invariant LAI dataset (FIX), an LAI specification based on CORINE land classes (LCB), and a MODIS satelliteretrieved dataset (MOD). The three datasets resolve increasingly higher moments both in time and space of LAI probability density functions and are therefore used to assess the sensitivity of surface variables to vegetation specification.

The intercomparison between the three datasets has shown that the MOD approach is the only one able to capture the expected vegetative cycle typical of the Mediterranean landscape. Using a land use-based LAI, as in the LCB dataset, does not introduce a significant variability in comparison to the unrealistic FIX database, which reveals the limitation of representing the vegetation variability with only a few classes. As a consequence, FIX and LCB predict very similar surface fluxes. Further, the comparison of LCB against the MOD dataset showed inadequacies of the land cover-based classification, in terms of LAI homogeneity, within the classes and lack of accurate description of the annual development. The obviously better LAI characterization of the MOD dataset suggests that accounting for LAI temporal and spatial variability is of potential benefit for the prevision of lower-level variables. Nevertheless, model biases of 2-m screen temperatures are not substantially reduced by the more detailed LAI specification when comparing with synoptic observing stations. Because 2-m temperatures are diagnostic variables calculated through the similarity theory (Stull 1988) from other boundary layer parameters that are highly uncertain, compensating errors can occur. To epitomize the role of LAI specification, a detailed validation of surface fluxes has been performed using long-term measurements collected by the CarboEurope project (Papale et al. 2006). It has been shown that the COSMO surface and vegetation scheme is unable to correctly partition incoming energy in latent and sensible heat fluxes: the former is always underestimated and the latter is always overestimated. On one hand, some of the discrepancies have been explained by noting that CarboEurope sites could not be representative of the vegetation over the whole model cell being located inside specific and homogeneous vegetative ecosystems. Nevertheless, it was proven that only part of the bias can be explained by the unresolved subgrid-scale variability of the vegetation inside the grid. In fact, at two of the CarboEurope sites, it was possible to compare LAI measurements with the predictions from the three datasets. In these two cases, LAI predictions were in almost perfect agreement with the observations. Nonetheless, the forecast of surface heat fluxes resulted in similar biases, perhaps because of a too-low soil moisture initialization.

Two main findings can be derived from this analysis. First, the comparison of the current description of LAI in the COSMO NWP model (the LCB approach) with satellite observations (MOD) leads to substantial differences, both quantitatively and in the annual development. Second, those differences have been shown to introduce substantial differences in model performance. Vegetation characteristics are not the only land surface parameters influencing the surface energy budget. Also, surface roughness, soil moisture, and the interactions between all of them have been found to be important (Sud et al. 1988; Collings and Avissar 1994; Niyogi et al. 1999). Better surface parameter descriptions are expected when new satellite-based observation systems become available. Determining the sensitivity and accuracy of the COSMO model to such changes in land surface parameters will need further investigation.

Acknowledgments. We thank Stephanie Faroux for providing us with data from the Ecoclimap project and Bodo Ritter for information about the modulation of LAI in the COSMO model. The CarboEurope project delivered the needed observation station data for flux comparison. We are indebted to Riccardo Valentini (University of Tuscia, Viterbo), Giorgio Matteucci (CNR 
ISAFoM), and Vincenzo Magliulo (CNR ISAFoM) for providing the data. Satellite data are distributed by the NASA MODIS Land Team. Thanks are given to Andrea Spisni for discussion on the expected LAI modulation over the Italian soil and to Adrian Tompkins for his kind revision of an earlier version of this manuscript. During this work, Christoph Knote was funded by the LEONARDO program of the European Union.

\section{REFERENCES}

Bartholomé, E., and A. S. Belward, 2005: GLC2000: A new approach to global land cover mapping from Earth observation data. Int. J. Remote Sens., 26, 1959-1977.

Champeaux, J. L., V. Masson, and F. Chauvin, 2005: ECOCLIMAP A global database of land surface parameters at $1 \mathrm{~km}$ resolution. Meteor. Appl., 12, 29-32.

Collings, D. C., and R. Avissar, 1994: An evaluation with the Fourier amplitude sensitivity test (FAST) of which land-surface parameters are of greatest importance in atmospheric modeling. J. Climate, 7, 681-703.

Commission of the European Communities, 1995: CORINE land cover. European Environment Agency Tech. Rep., 163 pp. [Available online at http://www.eea.europa.eu/publications/ COR0-landcover/at_download/file.]

Crawford, T. M., D. J. Stensrud, F. Mora, J. W. Merchant, and P. J. Wetzel, 2001: Value of incorporating satellite-derived land cover data in MM5/PLACE for simulating surface temperatures. J. Hydrometeor., 2, 453-468.

Dickinson, R., 1986: Biosphere-atmosphere transfer scheme (BATS) for the NCAR community climate model. National Center for Atmospheric Research Tech. Note NCAR/TN387+STR, 72 pp.

Doms, G., and Coauthors, 2004: A description of the non-hydrostatic regional model LM, Part II: Physical parameterization. Consortium for Small-Scale Modelling (COSMO) Rep. LM F90 3.20, $146 \mathrm{pp}$.

Fensholt, R., I. Sandholt, and M. Schultz Rasmussen, 2004: Evaluation of MODIS LAI, fAPAR and the relation between fAPAR and NDVI in a semi-arid environment using in situ measurements. Remote Sens. Environ., 91 (3-4), 490-507.

Freedman, J. M., D. R. Fitzjarrald, K. E. Moore, and R. K. Sakai, 2001: Boundary Layer clouds and vegetation-Atmosphere feedbacks. J. Climate, 14, 180-197.

Godfrey, C. M., and D. J. Stensrud, 2008: Soil temperature and moisture errors in operational Eta Model analyses. $J$. $H y$ drometeor., 9, 367-387.

Gregory, D., J.-J. Morcrette, C. Jakob, A. C. M. Beljaars, and T. Stockdale, 2000: Revision of convection, radiation and cloud schemes in the ECMMWF Integrated Forecasting System. Quart. J. Roy. Meteor. Soc., 126, 1685-1710.

Hammer, R. M., 1970: Cloud development and distribution around Khartoum. Weather, 25, 411-414.

Henderson-Sellers, A., 1993: A factorial assessment of the sensitivity of the BATS land-surface parameterization scheme J. Climate, 6, 227-247.

Hess, R., 2001: Assimilation of screen-level observations by variational soil moisture analysis. Meteor. Atmos. Phys., 77, 145-154

Jongen, S., and G. Bonafè, 2005: LAMI verification for air quality forecast and assessment purposes: case studies, special mea- surement campaigns, long-term evaluation. ARPA-SIM Tech. Rep, 85 pp.

Knyazikhin, Y., and Coauthors, 1999: MODIS leaf Area index (LAI) and fraction of photosynthetically active radiation absorbed by vegetation (FPAR) product (MOD15). NASA Goddard Space Flight Center Algorithm Theoretical Basis Document, 130 pp. [Available online at http://modis.gsfc. nasa.gov/data/atbd/atbd_mod15.pdf.]

Kurkowski, N. P., D. J. Stensrud, and M. E. Baldwin, 2003: Assessment of implementing satellite-derived land cover data in the Eta Model. Wea. Forecasting, 18, 404-416.

Louis, J. F., 1979: A parametric model of vertical eddy fluxes in the atmosphere. Bound.-Layer Meteor., 17, 187-202.

Loveland, T. R., B. C. Reed, J. F. Brown, D. O. Ohlen, Z. Zhu, L. Yang, and J. W. Merchant, 2000: Development of a global land cover characteristics database and IGBP DISCover from $1 \mathrm{~km}$ AVHRR data. Int. J. Remote Sens., 21, $1303-1330$

Mahfouf, J. F., 1991: Analysis of soil moisture from near-surface parameters: A feasibility study. J. Appl. Meteor., 30, 15341547.

Marletto, V., F. Ventura, G. Fontana, and F. Tomei, 2007: Wheat growth simulation and yield prediction with seasonal forecasts and a numerical model. Agric. For. Meteor., 147 (1-2), 71-79.

Masson, V., J. Champeaux, F. Chauvin, C. Meriguet, and R. Lacaze, 2003: A global database of land surface parameters at $1-\mathrm{km}$ resolution in meteorological and climate models. J. Climate, 16, 1261-1282.

Ministero dell'Agricoltura e delle Foreste, 1985: Inventario forestale nazionale. Istituto Sperimentale per l'Assestamento Forestale e per l'Alpicoltura Tech Rep., 463 pp. [Available online at http:// www.sian.it/inventarioforestale/jsp/1985_risultati_a.jsp.]

Monteith, J. L., 1995: Accommodation between transpiring vegetation and the convective boundary layer. J. Hydrol., 166 (3-4), 251-263.

Niyogi, D. S., S. Raman, and K. Alapaty, 1999: Uncertainty in the specification of surface characteristics, Part II: Hierarchy of interaction-explicit statistical analysis. Bound.-Layer Meteor., 91, 341-366.

Noilhan, J., and S. Planton, 1989: A simple parameterization of land surface processes for meteorological models. Mon. Wea. Rev., 117, 536-549.

Papale, D., and Coauthors, 2006: Towards a standardized processing of net ecosystem exchange measured with eddy covariance technique: Algorithms and uncertainty estimation. Biogeosciences, 3, 571-583.

Schraff, C., and R. Hess, 2003: A description of the nonhydrostatic regional model LM. Part III: Data assimilation. Consortium for Small-Scale Modelling (COSMO) Tech. Rep. LM F90 3.3, $85 \mathrm{pp}$.

Schrodin, R., and E. Heise, 2001: The multi-layer version of the DWD soil model TERRA_LM. Consortium for Small-Scale Modelling (COSMO) Tech. Rep. 2, 17 pp.

Segal, M., R. Avissar, M. McCumber, and R. A. Pielke, 1988: Evaluation of vegetation effects on the generation and modification of mesoscale circulations. J. Atmos. Sci., 45, 22682293.

, R. Arritt, C. Clarck, R. Rabin, and J. Brown, 1995: Scaling evaluation of the effect of surface characteristics on potential for deep convection over uniform terrain. Mon. Wea. Rev., 123, 383-400. 
Sellers, P. J., Y. Mintz, Y. C. Sud, and A. Dalcher, 1986: A simple biosphere model (SIB) for use within general circulation models. J. Atmos. Sci., 43, 505-531.

_ tion (SiB2) for atmospheric GCMs. Part I: Model formulation. J. Climate, 9, 676-705.

Simunek, J., M. Sejna, and M. van Genuchten, 2005: The HYDRUS-1D software package for simulating the one-dimensional movement of water, heat, and multiple solutes in variablysaturated media. University of California, Riverside Research Rep. 270 pp.

Stöckli, R., and P. L. Vidale, 2004: European plant phenology and climate as seen in a 20-year AVHRR land-surface parameter dataset. Int. J. Remote Sens., 25, 3303-3330.

Stull, R. B., 1988: An Introduction to Boundary Layer Meteorology. Kluwer Academic, 666 pp.
Sud, Y. C., J. Shukla, and Y. Mintz, 1988: Influence of land surface roughness on atmospheric circulation and precipitation: A sensitivity study with a general circulation model. J. Appl. Meteor., 27, 1036-1054.

Viterbo, P., and A. Beljaars, 1995: An improved land surface parameterization scheme in the ECMWF model and its validation. J. Climate, 8, 2716-2748.

Wetzel, P. J., and J.-T. Chang, 1988: Evapotranspiration from nonuniform surfaces: A first approach for short-term numerical weather prediction. Mon. Wea. Rev., 116, 600-621.

WMO, 1970: Maps of mean temperature and precipitation. Vol. 1, Climatic Atlas of Europe, WMO.

Yang, Z.-L., and R. E. Dickinson, 1995: Description of the biosphereatmosphere transfer scheme (BATS) for the Soil Moisture Workshop and evaluation of its performance. Global Planet. Change, 13, 117-134. 